\title{
Man-Nature Relationship in L P Devkota's Poems: An Ecological Study
}

\author{
Nabaraj Dhungel \\ Lecturer in English, Campus of International Languages, \\ Tribhuvan University, Kathmandu, Nepal
}

\section{Introduction}

Man-nature relationship is one of the central themes of great poet Laxmi Prasad Devkota. This relationship is both analogous and Antithetical. Nature is source of life, knowledge and pleasure foe human beings. But at the same time it is cruel and angry giving pain and suffering to human beings. Similarly, man both loves and exploits the nature. On the one hand, they worship nature as god but on the other hand, they make it the source of earning deteriorating it. Instead of enjoying its beauty and positively using nature, human beings try to get maximum profit from nature irrationally utilizing it which causes adverse effects in the ecosystem and the whole universe. Many of his poems focus on mundane elements of the human and the natural world.

Nature is both constructive and destructive. On the one hand everything comes out of nature and on the other everything goes back to it. Every living thing is born in nature, nourished by it and ultimately dies and disappears within it. Because of the creative force, nature generates and regenerates whereas because of its destructive force, it destroys and creates balance. Through such antithetical qualities and actions, nature gives us a lesson to move carefully and handle everything consciously. Moreover, nature's regenerative power helps everything survive and continue. For example, the dried and almost dead things in the winter get revived in the spring season because of the quality of nature. Therefore, nature holds pleasuregiving and pain-striking, generating and degenerating qualities.

Nature is the greatest artist as it generates different artistic things. There is divinity in nature. It can sacrifice itself for regeneration. When we look at the natural scenes like that of river, ocean, jungle, mountains, deserts, islands and plain lands, we find them quite beautiful which attract human beings. These things hold various artistic realities. Similarly, when we look at the giant animals like lion, elephant, rhino etc. and the smallest creatures like, ants, fleas, termites, etc., we wondered because of nature's quality of holding such antithetical things. The human-nature relationship also involves elements of philosophy as it concerns humankind's place in the world. In the same manner, man is also a part of nature. Man exists, enjoys and continues in nature and learns so many things from nature. From nature's quality of self-reliance, self-respect, self-creativity and selflessness, man also learns to be so. From its creative power, man 
learns to be creative. By looking at birds flying, man has become successful to fly high in the sky. Similarly, looking at the whale swimming, man now swims in the ocean with large ships. Man has invented so many things learning from the mechanism of nature itself. Moreover, man dwells upon nature as it is the largest house for him. So, nature is source of knowledge, inspiration and creativity for human beings. Likewise, nature is both destroyed and conserved by human beings. They destroy nature inventing poisonous chemicals and also preserve it through different rules and regulations with the understanding that man can be healthy only in healthy nature. Therefore, man and nature are inseparably interconnected.

\section{Objective of the Study}

The objective of the study is to explore and prove how nature of nature is both constructive and destructive and man-nature relationship is both analogous and antithetical. Through the use of environmental theory in Devkota's poems, the researcher presents "Her Grass Cutting Song" "The Springs" "Trees" "The Spring" "The Peasant" and "Charu" demonstrate man-nature relationship is that of part and whole whereas Muna Madan displays nature as the cause of suffering for man presenting difficult journey of Madan to Tibet due to cruel nature.

\section{Methodology}

The central theme of the study man-nature relationship has been researched from the theory of environmental literature. The Cooper and Carling's ideas of environmental determinism, Marten's idea of par and whole, Rousseau's notion of nature as original, Stan Rowe's eco-centrism, Timothy Clark's anthropocentrism and biocentrism, Bill Devall's deep ecology, Temple Grandin and Werner Herzog's nature as cruel, vile and indifferent have been used to demonstrate man-nature relationship as both analogous and antithetical as nature of nature is both constructive and destructive.

\section{Analysis}

Man cannot exist outside the environment as $\mathrm{s} / \mathrm{he}$ is a part of nature whole. According to Cooper and Carling, "we cannot imagine humankind existing outside of its environment - the evolution and history of humankind took place in this very environment which has its own history" (Ecologists, 18). There is even a movement, known as environmental determinism, which emphasizes the environment's role in the history of humankind.

Nature is the complete whole in which man is a small part. Therefore, man and nature are inseparable. "The physical and biological relationship between the rational being and nature is the same as the relationship between the part and the whole."(Marten, Human Ecology, 20). In the same spotlight, Devkota highlights through 
the poem "Her Grass Cutting Song" that man nature relationship is relationship of part and whole. He writes: Nature takes the green colour again / The young lady remains cutting grass / Rhododendron blossoms on her head again. "Her Grass Cutting Song" (9) (self trans.) there is a strong relationship between the grass and the girl. The flowers blossom on her head and make her beautiful and creative with the song. The regenerative quality of the nature adds beauty and creativity to her. She enjoys cutting grass and living with nature. As everything has a spirit, the world is also inhabited by the spirits of ancestors, and humans must avoid antagonism with things or nature. From this emerges the idea of harmony with the environment. Transgression of natural laws or failure to respect the spirits brings misfortune. Nature must be respected, as its components embody divine manifestations and spirits in different stages of spiritual evolution. The divine is omnipresent.

Ecocriticism puts emphasis on the relationship among humans, culture and nature. Environmentalism is divided on the question of whether to ascribe moral standing to humans, nonhuman entities, such as animals or entire ecosystems. Ecocritics discusses this relationship by using various concepts. Anthropocentrism, Bio-centrism, Eco-centrism and Deep Ecology are some. Timothy Clark in The Cambridge Introduction to Literature and the Environment states:

Anthropocentric is the world view where human beings are given the central position and all other entities are pushed to the margin. This privileging of one entity over the other gives rise to all sorts of power structure of exploitation. Anthropocentrism names any stance, perception or conception that takes the human as centre or norm. (3)

Anthropocentrism, which literally means "human-centered," is the view that all environmental responsibility is derived from human interests alone. Anthropocentrism places primary value on human beings and nature is attributed with instrumental and utilitarian value. The humans are seen as separate from nature and nature as object of study.

Eco-centrism is that holistic environmental theory, according to which not only living beings, but the whole ecosystem, including the abiotic part of nature, is worthy of moral consideration. Stan Rowe affirms eco-centrism as helping to solve the environmental crisis:

It seems to me that the only promising universal belief-system is Ecocentrism, defined as a value-shift from Homo sapiens to planet earth: Ecosphere. All organisms are evolved from Earth, sustained by Earth. Thus Earth, not organism, is the metaphor for Life. Earth not humanity is the Lifecenter, the creativity-center. Earth is the whole of which we are subservient 
parts. Such a fundamental philosophy gives ecological awareness and sensitivity an enfolding, material focus. (106)

The advocators of eco-centrism tend to resist the bio-centrist's exclusive concern for individual living organisms. Eco-centrism maintains that an adequate eco-ethics must take into account our relations with ecological systems, processes, along with non-living natural objects. The environmentalists who subscribe to ecocentrism contend that it is the key pathway to solve environmental crisis.

Deep ecology, being eco-centric philosophy, proposes new norms of human responsibility to change the human exploitation of nature into co-participation with nature. It believes in the fundamental interconnectedness of all life forms and natural features. According to Bill Devall, "Deep Ecological sense of self requires a further maturity and growth, an identification which goes beyond humanity to include the nonhuman world." (Deep Ecology,

67) Deep Ecologists believe that nature possesses the same moral standing and natural rights as human beings.

Rousseau (1712-1778) believed that original man, in his natural state, was entirely free and virtuous. If human beings were able to return to their "natural state" they would be happy forever after. The philosopher believed that children are born in a mythical state of nature, good, innocent and free; but later men are corrupted by society, science and art. So he invites people to return to the original state, living in harmony with nature as it is pure and uncorrupt. Similarly, Devkota glorifies the purity of nature in his poem associating with softness of a lady. He acclaims: "Splashing water, shining sun / Twinkling cloud wavering leaf / Grass straight red and full / Her active soft hand / Cutting grass with blossoming flowers" "Her Grass Cutting Song" (8) (self trans.) The shining sun, splashing water, twinkling cloud and wavering leaf of nature are combined with the grass cutter girl's soft hands.

Nature brightens human heart and mind through its hidden energy, electric quality and infinite potentiality. There is great good in returning to a landscape that has had extraordinary meaning in one's life. N. Scott Momaday states:

"There are certain villages and towns, mountains and plains that, having seen them, walked I them, lived in them, even for a day, we keep forever in mind's eye. They become indispensable to our well-being; they define us, and we say: I am who I am because I have been there" (Sacred and Ancestral Ground, 309).

The villages and towns in which we live define us and provide us dwelling and deep affection. Devkota asserts that the 'springs' from the mountain top brightens human heart removing darkness as it has mysterious and miraculous power to lighten up. 
I saw the springs falling down from the mountain top

Thousands of lights burnt bright in my heart

The hidden energy in the spring water

If we could see electric light burnt

But water flows melting vainly

We don't know the inner essence of it. (48 "The Springs", self trans. )

The 'springs' symbolizing nature shows the immeasurable inner force that brightens up human heart. It does the task of an electric light to remove darkness from the inner core of human heart.

Therefore, springs and humans are inseparable.

Nature is the greatest healer as it gives us spiritual satisfaction purifying our heart and head. It makes human life colourful. Gretel Ehrlich acclaims:

Nature adds multiple colours to human lives. It provides spiritual healing through purity and solace to heart and mind. Space has a spiritual equivalent and can heal what is divided and burdensome in us. Space represents sanity, not a life purified, dull, or spaced out but one that might accommodate intelligently any idea or situation. (The Solace of Open Spaces, 307).

Nature is a panacea as it can cure all the diseases providing spiritual solace to human beings and coloring their lives. It is the space that stands for beauty, sanity, purity and divinity. In the same manner, Devkota claims that nature, symbolized by air and trees, makes human life colourful. When life fades with mechanistic culture, nature refills colour regenerating and beautifying it. He argues:

A wide dense great tree stands before me

Its cool leaves in heavenly rest

My excited color of life flow in air

Expand its roots in heart and flowers full in branches. (28, "Trees", self trans.)

The branches, flowers and roots of the trees provide heavenly pleasure to human beings adding various colours to the faded lives making them ever green. Therefore, nature is source of life for human beings. Moreover, Gretel Ehrlich asserts:

Life is a cycle revolving around happiness and sadness, strength and weaknesses, fading and colouring, etc. A person's life is not a series of dramatic events for which he or she is applauded or exiled but a slow 
accumulation of days, seasons, years, fleshed out by the generational weight of one's family and anchored by land-bound sense of place. (302)

Life is the combination of all the entities that exist in nature. It consists of a cycle, seasons, days and years. It holds both positive and negative aspects as nature does. In the same spotlight, Devkota projects that the spring renews life removing all the negatives aspects of human lives. He displays:

Spring came spreading infinite magic

Soft beauty enchant emerged

Move air for growing and blossoming

Spreading pleasant lovely smell (42, “The Spring”, self trans.)

The spring arrives with the magical power renewing every almost dead thing. It shows the miraculous power of nature to rejuvenate everything that is in the fading stage. In the winter the things wither and dry but revive in the spring. It is cyclical and continuous. The continuity in human life is possible through continuity in nature.

Our inner space and the outer nature space are interrelated. There are landscapes, horizons and the surroundings in nature. Likewise, our inner landscape also holds a large soul, the horizons and the corners. Kathleen Norris claims:

There is a close relationship between the outer landscape (nature) and our inner landscape. Terence Kardong, a monk, isn't supposed to need all kinds of flashy surroundings. We are supposed to have a beautiful inner landscape. Watching a storm pass from horizon to horizon fills your soul with reverence. It makes your soul expand to fill the sky. (405, The Beautiful Places)

The outer space of nature and the inner space of human beings are interconnected sharing same characteristics. For Devkota, human soul and the tree soul communicate with each other in their own languages. No words suffice to express such essence of the inner core. He asserts:

Drying the sweat I speak lovely things

Loneliness becomes sweet with such company

Inner conversation between us without words

Words can't express that are in deep core of heart. (28, "Trees", self trans.)

Trees, which symbolize nature, remove our loneliness through the conversation inside. The relationship between man and nature is so much strong that it is inexpressible. Therefore, man and nature are inextricably interconnected.

The notion of birth is probably the deepest oldest meaning attached to the word nature. "Nature is what gives birth to us; nature is that wholeness of matter and space 
and time that holds and sustains us." (The Nature of Nature, 338) How we understand nature strongly influences how we act toward nature. But it is duality, doubleness that forms the center of our relationship with and inside nature. Nature is the source of all consciousness, religious experience and religious understanding. It is also mute, indifferent and radically non-intelligent. We got nature to find god. Devkota acclaims that nature is the true manifestation of god. There is intimate relationship between nature and the farmer. He depicts:

A pleasant place far at the corner

I don't know its village name

Blossoming peaches over the hut

Beauty arrives miraculous pure and nice. (35, "The Peasant", self trans.)

The peasant lives with the nature as his hut is covered with blossoming peaches. In the village, the farmer is born in nature, works in nature, enjoys with nature and dies in nature. It shows that nature is all in all for human beings. Moreover, the farmer enjoys the songs of birds in nature. He gets amazing pleasure from nature. He displays:

When the washer bird arrives and speaks

Walking with the spade on the shoulder

Looking at morning mountain steeple in the east

Drinking cold air with amazing pleasure "The Peasant" 36 self trans.

The farmer works in the field where he goes carrying the spade on the shoulder. It shows his diligence and dependence upon the field. He works in the field from the morning to the evening drinking cold water and air with immense pleasure that he gets from nature, it proves that nature is source of happiness, pleasure and life as a whole.

The relationship between nature and man is relationship of nail and muscle. It means that they cannot be disconnected. The scene becomes complete only when there is presence of both nature and man. Therefore, they are complementary to each other. Devkota opines that man and nature complete each other.

Separate place but bare hill nearby

Touches the Ganges going down

Big stones and much beautiful pure small

Her friends and continuous songs (39, "Charu”, Self trans.)

The voice of nature and the voice of human coalesce and merge together. The hills and mountains fall to the Ganges in the form of water with song like sound. In the same way, the beautiful girl sings a continuous sweet song raising her voice together with nature. Moreover, the humans can fill in gaps in nature and create a complete whole. Devkota further writes: 
Moving around the bushy ground

She plucks the beautiful flowers

She is in the scene filling it

She is bird of the earth doing all good. (39, "Charu" Self trans.)

Extremely close relationship exists between the girl and the bush, flowers and the earth. The girl fills the scene of nature with her sweet voice and song just like a bird. The beautiful flowers and the bushes inspire her to sing a song for all as a bird.

The man-nature relationship has always been ambiguous, nature being seen as both a provider and an enemy. Modern philosophers have views ranging from anthropocentrism to biocentrism and egocentrism. It is suggested to take a pragmatic approach by which primary human needs are met first and foremost whereas the needs of other living organisms and ecosystems are allowed to prevail over secondary human needs. Even though a plea is made to support the Earth Charter, which embodies in its principles and prescriptions a balanced respect for nature and future human generations, nature is not only constructive but also destructive.

Nature is also disparaging to human beings as they have to suffer a lot in nature. American Professor of Animal Science Temple Grandin in her book The Way I See It (2008) claims, "Nature is cruel but we don't have to be" (255). She boldly asserts that nature is cruel but we human beings should not be like that. In Devkota's Muna Madan, Madan's narration of the troublesome path to Lhasa when Muna requests him to take her with him depicts cruelty of nature. "Don't tell so, understand Muna, your feet are soft like flowers/ thorny jungle, stiff way, how can I take?" (12) Madan tries to convince her not to take her with him because of difficult ugly path to Lhasa. He shows his love to Muna claiming that her soft smooth feet cannot face ugly rough way which he is going to. Moreover, the path is ugly as there is fear of wild animals which can attack the human beings. In Muna Madan the dark and cloudy sky is ugly in comparison with the clear blue sky.

Hills and thorns, stiff mountains full of thousand hurdles

Way to Lhasa with stone and soil bare and treeless

Full mist full snow blossoming poison

Drizzling rain cold wind moving like cold ice (17)

The path is so difficult that it is poisonous to life because of icy cold atmosphere and deadly stiff mountains. The atmosphere is so frightening and lifeless that it can be taken as the most destructive form of nature.

Similarly, in Les Blank's documentary Burden of Dreams, Werner Herzog, the German writer - then in the process of filming his epic period piece Fitzcarraldo deep in the Peruvian jungle - rants against the obscenity of his lushly overgrown surroundings. "Nature here is vile and base," he says. "The trees here are 
in misery, and the birds are in misery. I don't think they sing. They just screech in pain. It's an unfinished country. It's still pre-historical." He means to say that nature is despicable. Furthermore, in the film Grizzly Man (2005), Warner as a narrator says, "I discover no kinship, no understanding, no mercy. I see only the overwhelming indifference of nature." For him, nature is indifferent to humans and animals. The more Madan walks on the way to Lahsa, the more complicated it becomes. He has to face so many ups and downs. Nature shows her cruelty o Madan during his journey. Devkota describes cruelty of nature describing the way:

The narrow stiff cliff

The rope-like bridge and the dizzy top mountains

High altitude breaking heart and lungs

Stony teeth on the way edgy and uncomfortable

Snowy teeth sharp storm rattling the teeth (19-20)

The journey is full of sufferings because of narrow cliffs, rope-like bridge and teeth rattling snowy cold atmosphere. The description shows that the path is dreadful as if there is no other such dangerous way.

When the nature and circumstance become too much unfavorable to man, ugliness surrounds him. When Madan is helpless in the jungle after desertion of his friends, he notices everything around him anti-life though he has a strong hope and desire for life. Devkota describes:

Darkness arose in jungle, the air slept

All birds stopped twittering and singing, the cold troubled

Bad fortune so all jungles and hills were cruel

Cruel stars, cruel world total bareness. (32)

The ugliest thing of nature cast here is Madan's sufferings in nature. Because of darkness, silence of birds and stagnancy of the air, pessimism exceeds. All the jungles, hills, stars and the whole world are cruel which do not support life.

\section{Conclusion}

To conclude, Devkota's poems ascertain that man-nature relationship is both positive and negative- both friendly and rival. On the one hand, nature can be the source of pleasure and knowledge and life as a whole for human beings. Man can learn and get so many things from nature for his survival and advancement. Nature can also be the inspiration for creativity as it is manifestation of god himself. In addition, the relationship of man and nature is relationship of part and whole which complement each other. Devkota's poems "Her Grass Cutting Song", "The Springs", "Trees", "The Spring", "The Peasant" and "Charu" show that man and nature have relationship of part and whole. On the other hand, both nature and human are destructive for each other. Man can destroy nature and nature also can show cruelty causing suffering to man. 
Nature can show demonic face and behavior to man troubling him. Devkota's Muna Madan projects nature as source of trouble and pain for the man showing difficult journey of Madan to Tibet due to cruel nature. Therefore, man-nature relationship is antithetical. Whatsoever, man and nature are inextricably connected with each other as they complete each other harmoniously or discordantly. Through the poems, Devkota challenges anthropocentrism highlighting on eco-centrism with the shift from egoconsciousness to eco-consciousness projecting both association and disassociation between man and nature.

\section{Works Cited}

Anderson Chris and Lex Runciman. A Forest of Voices: Reading and Writing the Environment. California, Mayfield Pub Co., 1995.

Clark, Timothy. The Cambridge Introduction to Literature and the Environment. Cambridge:

Cambridge University Press, 2011.

Cooper, N.S. and R.C.J. Carling. Ecologists and Ethical Judgements. New York, Science Publishers, Inc., 1999.

Devall, Bill and George Sessions Deep Ecology. Salt Lake City: Gibbs M. Smith, Inc., 1985.

Devkota, Laxmi Prasad. Muna Madan. Kathmandu, Manjari Publication, 2073 Edition. . Bhikhari. Kathmandu, Sajha Prakasan, 2073 Edition.

Grandin, Temple. The Way I See It. Arlington, Future Horizons, 2008.

Herzog, Warner. Burden of Dreams. USA. 1982. . Grizzly Man. USA. 2005.

Marten, Gerry. Human Ecology. London, Earthscan Publications Ltd., 2001.

Rowe, Stan J. "Eco-centrism: the Chord that Harmonizes Humans and Earth." The Trumpeter 11.2 (1994): 106-107. JSTOR. Web 12 May 2017. 